\title{
3 Research Square

\section{MiR-486-5p represses chondrocyte multiplication but facilitates their deaths in congenital microtia through aiming at H3F3B}

\section{Ying Liu}

Plastic Surgery Hospital, Chinese Academy of Medical Sciences, Peking Union Medical College Ling Zhang

Plastic Surgery Hospital, Chinese Academy of Medical Sciences, Peking Union Medical College

\section{Weiwei Dong}

Plastic Surgery Hospital, Chinese Academy of Medical Sciences, Peking Union Medical College

Qinghua Yang ( $\square$ afdhrr@yeah.net )

Plastic Surgery Hospital, Chinese Academy of Medical Sciences, Peking Union Medical College https://orcid.org/0000-0002-8167-4933

\section{Research Article}

Keywords: miR-486-5p, Congenital microtia, Proliferation, Apoptosis

Posted Date: April 8th, 2021

DOI: https://doi.org/10.21203/rs.3.rs-347227/v1

License: (c) (i) This work is licensed under a Creative Commons Attribution 4.0 International License. Read Full License 


\section{Abstract \\ Background}

MicroRNAs have been reported to play important roles in the development of external ear. The present study was designed to explore the expression patterns and biological function of miR-486-5p in congenital microtia.

\section{Methods}

Cartilage tissue specimens were collected from congenital microtia cases who received reconstructive ear surgeries, while the normal cartilage tissues from other otology surgeries were adopted as normal controls. The relative expression of miR-486-5p was investigated by quantitative-real time polymerase chain reaction. The potential target of miR-486-5p was explored by TargetScanHuman 7.2 and dualLuciferase reporter assay. MTT and flow cytometry assays were adopted to investigate cell proliferation and apoptosis, respectively.

\section{Results}

The expression of miR-486-5p was significantly up-regulated in microtia cartilage tissues. Knockdown of miR-486-5p in microtia chondrocytes enhanced proliferation and inhibited apoptosis. H3F3B might be a target of miR-486-5p, and miR-486-5p could regulate proliferation and apoptosis of microtia chondrocytes by targeting H3F3B. Moreover, the enforced expression of H3F3B could re-turned the function of miR-486-5p in microtia chondrocytes.

\section{Conclusion}

Up-regulation of miR-486-5p may inhibit microtia chondrocytes proliferation and promote apoptosis by targeting $H 3 F 3 B$.

\section{Background}

Microtia is a kind of congenital malformation in external and middle ear [1]. According to the statistics, the prevalence of microtia is about $0.83-17.4 / 10000$ newborns $[2,3]$ and its vary depends on race, gender, and region [4-6]. The severity of microtia is ranged from slight ear defect to complete absence of the ear [6]. The occurrence of microtia is a complex multifactorial disease influenced by genetic and environmental factors $[7,8]$. In previous studies, the education level and age of mother, history of disease in early pregnancy, childbearing and abortion histories, smoking and drinking during pregnancy are the risk factors of microtia [9-12]. However, only a fraction of individuals exposure to the above risk factors suffer from microtia, so genetic factors play the vital role in microtia occurrence. 
MicroRNAs (miRNAs) are a class of small non-coding RNA in the length of about 18-25 nucleotides [13]. They can regulate the expression of targeted mRNA through binding to 3'UTR of target gene in posttranscriptional level [14]. MiRNAs have been reported to be involved in multiple biological behaviors, such as cell proliferation, differentiation, cycle and apoptosis $[15,16]$. The abnormal expression of miRNAs are found in congenital microtia patients [17]. miR-486-5p is a common member of miRNAs family and widely studied in various diseases $[18,19]$. It is reported to participate in the proliferation, apoptosis and metastasis of cells and may be as the promising diagnostic and prognostic biomarkers for some diseases [20]. miR-486-5p can inhibit the proliferation and migration of chondrocytes through regulating some important genes and/or pathways [21]. It is also found to be possibly involved in the development and advancement of microtia [22]. However, the exact role of miR-486-5p in the occurrence of microtia and the relative molecular mechanism are rarely explored in the previous studies.

Therefore, in the present study, we aimed to investigate the expression level of miR-486-5p in the cartilage tissues of congenital microtia patients and reveal its promising mechanism in microtia progression.

\section{Methods}

\section{Patients and samples}

In this research, 112 congenital microtia cases were enrolled in the Otorhinolaryngologic Department of Plastic Surgery Hospital, Chinese Academy of Medical Sciences, Peking Union Medical College and they conformed to the diagnostic criteria of congenital microtia. The cartilage tissues were obtained from congenital microtia patients receiving ear reconstruction and immediately put into liquid nitrogen, then transferred to $-80^{\circ} \mathrm{C}$ refrigerator. At the same time, 104 individuals with normal ear receiving other ear operations were as the controls and their cartilage tissues of ear were obtained in surgery. The handling and storage of samples in the controls were as the cases. The controls were frequency-matched with the cases in age and gender.

All subjects were Chinese Han population without any blood relationship each other. This study obtained the support of the Ethics Committee of Plastic Surgery Hospital, Chinese Academy of Medical Sciences, Peking Union Medical College and the whole study research process was informed all subjects. Written consents were signed by all study subjects.

\section{RNA extraction and QRT-PCR assay}

Totol RNA of cartilage tissue in congenital microtia patients and normal individuals were isolated using Trizol reagent (BBI, Kitchener, Ont., Canada) following the producer's specification. Then total RNA was as the template to synthesize cDNA using the RevertAdiTM First Strand cDNA Synthesis Kit (Ferments, Glenn Burnie, Md., USA). qRT-PCR reaction was conducted by the SYBR Green PCR master mix (Applied Biosystems, USA) on the 7300 Real-Time PCR System (Applied Biosystems, USA). U6 was as the internal reference to normalize the expression of miR-486-5p. Its relative expression was counted by $2^{-\Delta \Delta C t}$ method. Every samples were repeated at least 3 times. 


\section{Cell culture}

Firstly, we isolated cartilage cells from cartilage tissue of congenital microtia cases through $0.25 \%$ trypsin

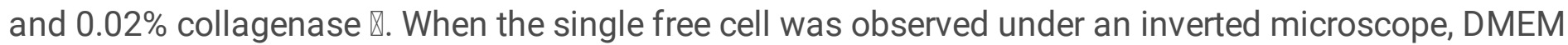
media was added to dilute collagenase $\mathbb{\Delta}$ solution for termination of the digestion, filtration, centrifugation at $1500 \mathrm{r} / \mathrm{min}$ for $5 \mathrm{~min}$. Abandon supernatant, resuspended and putting into $37^{\circ} \mathrm{C}, 5 \% \mathrm{CO}_{2}$ incubator. Nutrient solution was replaced three days at a time.

\section{Cell transfection}

When the cells were in logarithmic phase, they were conducted transfection. miR-486-5p mimics, inhibitors and corresponding negative control (NC) were respectively transfected into cartilage cells applying Lipofectamine 2000 (Invitrogen, CA, USA) following the producers' protocol. Then they were cultured at $37^{\circ} \mathrm{C}$ containing $5 \% \mathrm{CO}_{2}$ for $48 \mathrm{~h}$. The transfection efficiency was detected using qRT-PCR method.

\section{Cell proliferation assay}

Cell proliferation ability was checked by MTT assay following the standardized protocol (Roche). After transfection, cartilage cells were inoculate in 96 -well plates and the density of cells was adjusted to $2 \times 10^{4} /$ well. All groups were incubated for oh, $24 \mathrm{~h}, 48 \mathrm{~h}$ and $72 \mathrm{~h} .50 \mu \mathrm{l} \mathrm{MTT}$ reagent $(5 \mathrm{mg} / \mathrm{mL})$ was added into every well, then $37^{\circ} \mathrm{C}$ incubation for $4 \mathrm{~h}$. The proliferation ability were determined using MTT cell proliferation kit (Cayman Chemical) based on the instruction. MTT enzyme-linked immunometric meter was used to measure OD value $(570 \mathrm{~nm})$ so as to indicate the proliferation ability of cells .

\section{Apoptosis assay}

Cells were seeded into 24 well plates in the density of $1 \times 10^{6} / \mathrm{ml}$ and incubated at $37^{\circ} \mathrm{C}, 5 \% \mathrm{CO}_{2}$ incubator overnight. Added $10 \mu \mathrm{L} \mathrm{PI}$ and $400 \mu \mathrm{L}$ Annexin V-FITC (BD Biosciences, Detroit, MI, USA) in one after another to cells, incubated for $20 \mathrm{~min}$ at room temperature, dark. Then flow cytometer was used to analyze the situation of cell apoptosis.

\section{Double luciferase report assay}

To explore the mechanisms of miR-486-5p in congenital microtia, TargetScanHuman 7.2 (updated March 2018) database analysis was used to investigate its targeted mRNAs. We found that miR-486-5p could bind to 3 'UTR of $H 3 F 3 B$ gene. To verify the target relationship between miR-486-5p and H3F3B, luciferase reporter assay was adopted. The $3^{\prime} \mathrm{UTR}$ region of $H 3 F 3 B$ gene (H3F3B-wt), as well as the mutant $3^{\prime} \mathrm{UTR}$ region which did not contain the complementary sequence of miR-486-5p (H3F3B-mut), was synthesized and ligated into the luciferase reporter vector pGL3 (Promega, USA) following the production instruction. Then $H 3 F 3 B$-wt and $H 3 F 3 B$-mut were respectively cotransfected with miR-486-5p mimics or mimic-NC into cartilage cells by Lipofectamine ${ }^{\circledR} 2000$ reagent (Invitrogen; Thermo Fisher Scientific, Inc.). After 
incubation for $48 \mathrm{~h}$, the transfected cells were harvested, and their luciferase activity was evaluated using dual-luciferase reporter assay system (Promega Corporation) following the instruction.

\section{Western blot}

Cartilage tissues were lysed using radio immunoprecipitation assay (RIPA) buffer (Thermo Scientific, Belmont, MA, USA) at $4^{\circ} \mathrm{C}$ for $30 \mathrm{~min}$. Proteins of cartilage tissues were extracted and isolated by $10 \%$ sodium dodecyl sulfonate-polyacrylamide gel electrophoresis (SDS-PAGE). They were transferred onto a PVDF membrane (Roche) and then were blocked by nonfat milk at $4^{\circ} \mathrm{C}$ for overnight. Then it was incubated by primary antibodies anti-H3F3B (1:1000) (Abcam, Cambridge, UK) at $4^{\circ} \mathrm{C}$ for overnight, GAPDH was as the internal reference, then were incubated at room temperature for $1.5 \mathrm{~h}$ using second antibody (1:2000, Abcam, Cambridge, UK). The target band of protein was showed using ECL Western blotting kit (Millipore, Boston, MA, USA) according to the producers' instruction.

\section{Statistical analysis}

SPSS 18.0 software (SPSS Inc., Chicago, IL, USA) was used for data statistics analysis and figures were plotted by GraphPad Prism (GraphPad, San Diego, CA, USA) software. All experiments were repeated at least in triplicate and the data were expressed using mean \pm SD (standard deviation). The difference between groups was compared by two-tailed Student's t-test or $\chi^{2}$ test. $P<0.05$ was considered as the statistically significant difference.

\section{Results}

\section{Up-regulated expression of miR-486-5p in cartilage tissues of congenital microtia}

We measured the expression level of miR-486-5p in cartilage tissues of congenital microtia patients and the controls by qRT-PCR. The results showed that miR-486-5p expression level was obviously upregulated in cartilage tissues of congenital microtia patients, compared with the controls $(P<0.001$, Fig. 1).

\section{The baseline data of congenital microtia patients and normal controls}

We compared the baseline information of congenital microtia patients and normal controls by $\chi^{2}$ test. The average age of the two groups were respectively $15.26 \pm 10.23$ and $16.61 \pm 9.86$ years old. There was no significant difference between the two groups in age $(P=0.239)$. The number of males and females in congenital microtia patients were 51 and 61,43 and 59 in normal controls, the difference was not significant $(P=0.619)$. We didn't find the difference between the two groups in body mass index (BMI), either $(P=0.567)$. The data were showed in Table 1 . 
Table 1

The clinical features of study subjects in the case and control groups

\begin{tabular}{|llll|}
\hline Characteristic & Cases $\mathbf{n = 1 1 2}$ & Control $\mathrm{n}=102$ & $\boldsymbol{P}$ \\
\hline Age & $15.26 \pm 10.23$ & $16.61 \pm 9.86$ & 0.239 \\
Gender & & & 0.388 \\
Male & 81 & 79 & \\
Female & 31 & 23 & \\
BMl $\left(\mathrm{kg} / \mathrm{m}^{2}\right)$ & $23.69 \pm 3.21$ & $24.13 \pm 2.84$ & 0.5671. \\
\hline BMl: body mass index & & \\
\hline
\end{tabular}

The influence of miR-486-5p on the proliferation and apoptosis of cartilage cells in congenital microtia

In this study, we transfected miR-486-5p mimics and mimic-NC into cartilage cells from cartilage tissues of congenital microtia patients. We found that the proliferation ability of cartilage cells was obviously lower in miR-486-5p mimics transfection group than that in the mimic-NC group $(P<0.05$, Fig. 2$)$. Meanwhile, the apoptosis of cartilage cells in miR-486-5p mimics group was significantly enhanced, compared with mimic-NC group $(P<0.05$, Fig. 3$)$.

\section{H3F3B was as the target gene of miR-486-5p}

The targeted relationship of miR-486-5p with $H 3 F 3 B$ was predicted by TargetScanHuman 7.2 website (Fig. 4A) and verified through double luciferase report assay. The results showed that miR-486-5p inhibitor significantly enhanced the luciferase activity of cartilage cells with $H 3 F 3 B$-wt in comparison with inhibitor-NC co-transfection group $(P<0.01$, Fig. 4B). However, in cartilage cells with $H 3 F 3 B$-mut, there was no obvious different in luciferase activity between miR-486-5p inhibitors and inhibitor-NC groups ( $P>$ 0.05). Moreover, we found that the knockdown of miR-486-5p could remarkably promote the expression of $H 3 F 3 B$ in cartilage cells $(P<0.001$, Fig. 4 C). Additionally, H3F3B mRNA and protein levels were found the significantly down-regulated expression in cartilage tissues of congenital microtia patients, compared with individuals with normal ear $(P<0.001$, Fig. 4D).

\section{miR-486-5p regulated the proliferation and apoptosis of cartilage cells in congenital microtia through} H3F3B

In our research, we also detected whether miR-486-5p mimics inhibited proliferation and promote apoptosis of cartilage cells trough directly targeting H3F3B. Firstly, we conducted the overexpression of $H 3 F 3 B$ by pcDNA3.1 vector (OE-H3F3B) and empty-vector (OE-NC) was as the control. miR-486-5p mimics and $\mathrm{OE}-\mathrm{H} 3 \mathrm{~F} 3 \mathrm{~B}$ was respectively and together transfected into cartilage cells. The results showed that H3F3B overexpression significantly reversed the inhibited proliferation ability resulted from miR-486-5p 
mimics transfection ( $P<0.05$, Fig. 5A). Furthermore, enhanced $H 3 F 3 B$ expression also obviously reversed the promoted role of apoptosis caused by miR-486-5p overexpression in cartilage cells of congenital microtia $(P<0.01$, Fig. 5B and C).

\section{Discussion}

In the current study, we explored the expression level of miR-486-5p in cartilage tissues of congenital microtia. The results showed that miR-486-5p expression was obviously up-regulated in cartilage tissues of congenital microtia in comparison to normal ear. In previous study, Li reported that 6 miRNAs were significantly up-regulated expression in the microtic group, compared with the normal controls, including miR-486-5p [22]. In the study of Wei, miR-486-5p expression was also found to be significantly higher in congenital microtia than that in the normal controls [17]. Our results were consistent with the previous studies. Hence, miR-486-5p plays an important role in the development of congenital microtia.

Microtia is a consequence of genetic factors combined with environmental factors [23]. So far, a number of genetic factors have been discovered to participate in the onset of microtia, including multiple miRNAs. For instance, miR-193b-3p can promote the synthesis of chondrocyte extracellular matrix (ECM) in microtia patients [24]. In the research of $\mathrm{Li}, 6$ up-regulated miRNAs and 5 down-regulated miRNAs were identified in microtic patients [22]. Moreover, some environmental factors are also reported to be involved in microtia occurrence, such as season and sex [25]. However, in our study, we found that there was no significant association between age, gender or BMI and microtia etiology.

Meanwhile, in our study, we also explored the possible mechanism of miR-486-5p influencing microtia development. The results showed that miR-486-5p overexpression significantly inhibited the proliferation ability of chondrocytes in microtia, moreover, it also promoted the apoptosis of chondrocytes. miR-486-5p may regulate the progression of microtia through influencing its chondrocyte proliferation and apoptosis. In previous study, miR-486-5p was considered to inhibit the proliferation and migration of chondrocytes in osteoarthritis [21]. It also inhibited inflammatory response, ECM degradation and apoptosis of nucleus pulposus cells [26]. So, our outcomes were similar to the published articles.

Usually, miR-486-5p is found to take part in the development of disease through targeting some genes. Liu reported that miR-486-5p inhibited cell proliferation and induced apoptosis of leukemia cells by targeting FOXO1 [27]. It also promoted the cell proliferation, migration, invasion of endometrial carcinoma by through targeting MARK1 [28]. H3F3B plays the key role in the maturation and differentiation of chondrocyte [29] and serves as a target gene of miR-486-5p according to the report [30] and database analysis. However, whether miR-486-5p influences the progression of microtia through targeting $H 3 F 3 B$ is rarely explored in previous study. Our study found that $H 3 F 3 B$ expression was remarkably down-regulated in microtia patients in comparison to normal controls. miR-486-5p knockdown inhibited the luciferase activity in chondrocytes with $H 3 F 3 B$-wt, but not $H 3 F 3 B$-mut cells. Moreover, the knockdown of miR-486-5p significantly enhanced $H 3 F 3 B$ expression, which indicated $H 3 F 3 B$ was a target gene of miR-486-5p. in addition, the rescue assays showed that $H 3 F 3 B$ overexpression obviously reversed the inhibited role 
caused by miR-486-5p mimics transfection for chondrocyte proliferation and promoted role for the apoptosis. Hence, miR-486-5p inhibited the proliferation and promoted the apoptosis of cartilage cells in congenital microtia through targeting $H 3 F 3 B$.

Although our study obtained some achievements about the expression pattern of miR-486-5p in congenital microtia and the potential mechanism, several shortcomings should be paid attention. Firstly, the sample size was relatively small, which might cause the result deviation. Only one population was included in this study, the practicability was limited. Multiple target genes of miR-486-5p are reported, but only $H 3 F 3 B$ was explored in our study. Besides, in vivo experiment was not conducted to verify our results. Therefore, further studies are needed to overcome the above limitations and verify the present outcomes.

\section{Conclusions}

In conclusion, miR-486-5p is remarkably up-regulated in cartilage tissues of congenital microtia. It inhibits the proliferation of cartilage cells and promotes apoptosis through targeting $H 3 F 3 B$.

\section{Abbreviations}

Negative control (NC)

Radio immunoprecipitation assay (RIPA)

Sodium dodecyl sulfonate-polyacrylamide gel electrophoresis (SDS-PAGE)

Empty-vector (OE-NC)

Extracellular matrix (ECM)

\section{Declarations}

\section{Ethics approval and consent to participate}

This study was supported by the Ethics Committee of Plastic Surgery Hospital, Chinese Academy of Medical Sciences, Peking Union Medical College and also has been carried out in accordance with the World Medical Association Declaration of Helsinki.

The subjects had been informed the objective. Certainly, written consents were signed by every subject in this study.

\section{Consent for publication}

We obtaining permission from participants to publish their data. 
Availability of data and materials

All data generated or analysed during this study are included in this published article.

\section{Competing interests}

The authors declare that they have no competing interests.

\section{Funding}

Not applicable.

\section{Authors' contributions}

Y.L. design of the work; L.Z. the acquisition, analysis, W.D. interpretation of data; Q.Y. the creation of new software used in the work; Y.L. have drafted the work or substantively revised it. All authors read and approved the final manuscript.

\section{Acknowledgements}

Not applicable.

\section{References}

1. Lee KT, Yang EJ, Lim SY, Pyon JK, Mun GH, Bang SI, Oh KS. Association of congenital microtia with environmental risk factors in South Korea. Int J Pediatr Otorhinolaryngol. 2012;76(3):357-61.

2. Luquetti DV, Heike CL, Hing AV, Cunningham ML, Cox TC. Microtia: epidemiology and genetics. American journal of medical genetics Part A. 2012;158A(1):124-39.

3. Shibazaki-Yorozuya R, Nagata S. Preferential Associated Malformation in Patients With Anotia and Microtia. J Craniofac Surg. 2019;30(1):66-70.

4. Suutarla S, Rautio J, Ritvanen A, Ala-Mello S, Jero J, Klockars T. Microtia in Finland: comparison of characteristics in different populations. Int J Pediatr Otorhinolaryngol. 2007;71(8):1211-7.

5. Canfield MA, Langlois PH, Nguyen LM, Scheuerle AE. Epidemiologic features and clinical subgroups of anotia/microtia in Texas. Birth defects research Part A Clinical molecular teratology. 2009;85(11):905-13.

6. Chen X, Zhang R. Microtia epigenetics: An overview of review and new viewpoint. Medicine. 2019;98(41):e17468.

7. Lu M, Lu X, Jiang H, Pan B. Review of Preferential Suspicious Genes in Microtia Patients Through Various Approaches. J Craniofac Surg. 2020;31(2):538-41.

8. Ryan MA, Olshan AF, Canfield MA, Hoyt AT, Scheuerle AE, Carmichael SL, Shaw GM, Werler MM, Fisher SC, Desrosiers TA. Sociodemographic, health behavioral, and clinical risk factors for 
anotia/microtia in a population-based case-control study. Int J Pediatr Otorhinolaryngol. 2019;122:18-26.

9. Deng K, Dai L, Yi L, Deng C, Li X, Zhu J. Epidemiologic characteristics and time trend in the prevalence of anotia and microtia in China. Birth defects research Part A Clinical molecular teratology. 2016;106(2):88-94.

10. Hoyt AT, Canfield MA, Shaw GM, Waller DK, Polen KN, Ramadhani T, Anderka MT, Scheuerle AE: Sociodemographic and hispanic acculturation factors and isolated anotia/microtia. Birth defects research Part A, Clinical and molecular teratology 2014, 100(11):852-862.

11. Stern RS, Rosa F, Baum C. Isotretinoin and pregnancy. J Am Acad Dermatol. 1984;10(5 Pt 1):851-4.

12. Du JM, Guo WH, Han J, Zhuang HX. [Case control study on risk factors of congenital microtia]. Zhonghua er bi yan hou tou jing wai ke za zhi = Chinese. journal of otorhinolaryngology head neck surgery. 2006;41(2):107-11.

13. Saliminejad K, Khorram Khorshid HR, Soleymani Fard S, Ghaffari SH. An overview of microRNAs: Biology, functions, therapeutics, and analysis methods. Journal of cellular physiology. 2019;234(5):5451-65.

14. Lu TX, Rothenberg ME: MicroRNA. The Journal of allergy and clinical immunology 2018, 141(4):1202-1207.

15. Mens MMJ, Ghanbari M. Cell Cycle Regulation of Stem Cells by MicroRNAs. Stem cell reviews reports. 2018;14(3):309-22.

16. Morales S, Monzo M, Navarro A. Epigenetic regulation mechanisms of microRNA expression. Biomolecular concepts. 2017;8(5-6):203-12.

17. Wei G. Bioinformatics analysis of microRNA comprehensive regulatory network in congenital microtia. Int J Pediatr Otorhinolaryngol. 2015;79(10):1727-31.

18. Hu H, Xu H, Lu F, Zhang J, Xu L, Xu S, Jiang H, Zeng Q, Chen E, He Z. Exosome-Derived miR-486-5p Regulates Cell Cycle, Proliferation and Metastasis in Lung Adenocarcinoma via Targeting NEK2. Front Bioeng Biotechnol. 2020;8:259.

19. Lopez-Bertoni H, Kotchetkov IS, Mihelson N, Lal B, Rui Y, Ames H, Lugo-Fagundo M, Guerrero-Cazares $\mathrm{H}$, Quinones-Hinojosa A, Green JJ, et al. A Sox2:miR-486-5p Axis Regulates Survival of GBM Cells by Inhibiting Tumor Suppressor Networks. Cancer research. 2020;80(8):1644-55.

20. Li C, Zheng X, Li W, Bai F, Lyu J, Meng QH. Serum miR-486-5p as a diagnostic marker in cervical cancer: with investigation of potential mechanisms. BMC Cancer. 2018;18(1):61.

21. Shi J, Guo K, Su S, Li J, Li C. miR4865p is upregulated in osteoarthritis and inhibits chondrocyte proliferation and migration by suppressing SMAD2. Mol Med Rep. 2018;18(1):502-8.

22. Li C, Hao S, Wang H, Jin L, Qing F, Zheng F, Zhang P, Chen L, Ma D, Zhang T. MicroRNA expression profiling and target genes study in congenital microtia. Int $\mathrm{J}$ Pediatr Otorhinolaryngol. 2013;77(4):483-7. 
23. Gendron C, Schwentker A, van Aalst JA. Genetic Advances in the Understanding of Microtia. Journal of pediatric genetics. 2016;5(4):189-97.

24. Chen X, Zhang R, Zhang Q, Xu Z, Xu F, Li D, Li Y. Chondrocyte sheet in vivo cartilage regeneration technique using miR-193b-3p to target MMP16. Aging. 2019;11(17):7070-82.

25. Liu L, Pan B, Lin L, Yu X, Yang Q, Zhao Y, Zhuang H, Jiang H. Seasonal variation in months of birth of patients with microtia in a Chinese population. Int J Pediatr Otorhinolaryngol. 2011;75(6):782-4.

26. Chai X, Si H, Song J, Chong Y, Wang J, Zhao G. miR-486-5p Inhibits Inflammatory Response, Matrix Degradation and Apoptosis of Nucleus Pulposus Cells through Directly Targeting FOXO1 in Intervertebral Disc Degeneration. Cellular physiology biochemistry: international journal of experimental cellular physiology biochemistry pharmacology. 2019;52(1):109-18.

27. Liu H, Ni Z, Shi L, Ma L, Zhao J: MiR-486-5p inhibits the proliferation of leukemia cells and induces apoptosis through targeting FOX01. Molecular and cellular probes 2019, 44:37-43.

28. Zheng X, Xu K, Zhu L, Mao M, Zhang F, Cui L: MiR-486-5p Act as a Biomarker in Endometrial Carcinoma: Promotes Cell Proliferation, Migration, Invasion by Targeting MARK1. OncoTargets and therapy 2020, 13:4843-4853.

29. Abe S, Nagatomo H, Sasaki H, Ishiuchi T. A histone H3.3K36M mutation in mice causes an imbalance of histone modifications and defects in chondrocyte differentiation. Epigenetics 2020:112.

30. Peng X, Wei F, Hu X. Long noncoding RNA DLGAP1-AS1 promotes cell proliferation in hepatocellular carcinoma via sequestering miR-486-5p. Journal of cellular biochemistry. 2020;121(2):1953-62.

\section{Figures}




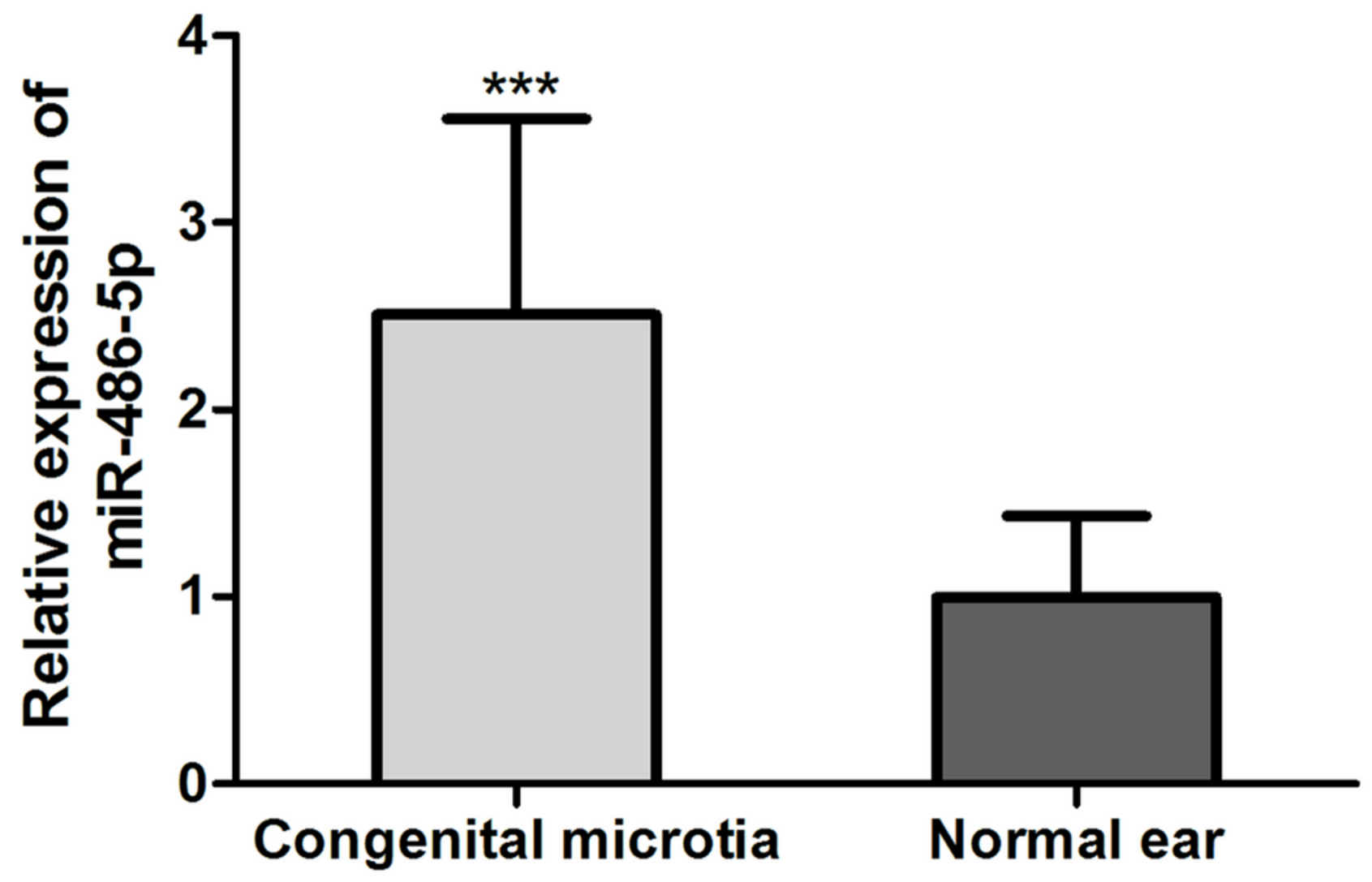

Figure 1

The expression level of miR-486-5p in cartilage tissue of congenital microtia and normal ear. ${ }^{\star \star \star} P<0.001$. 


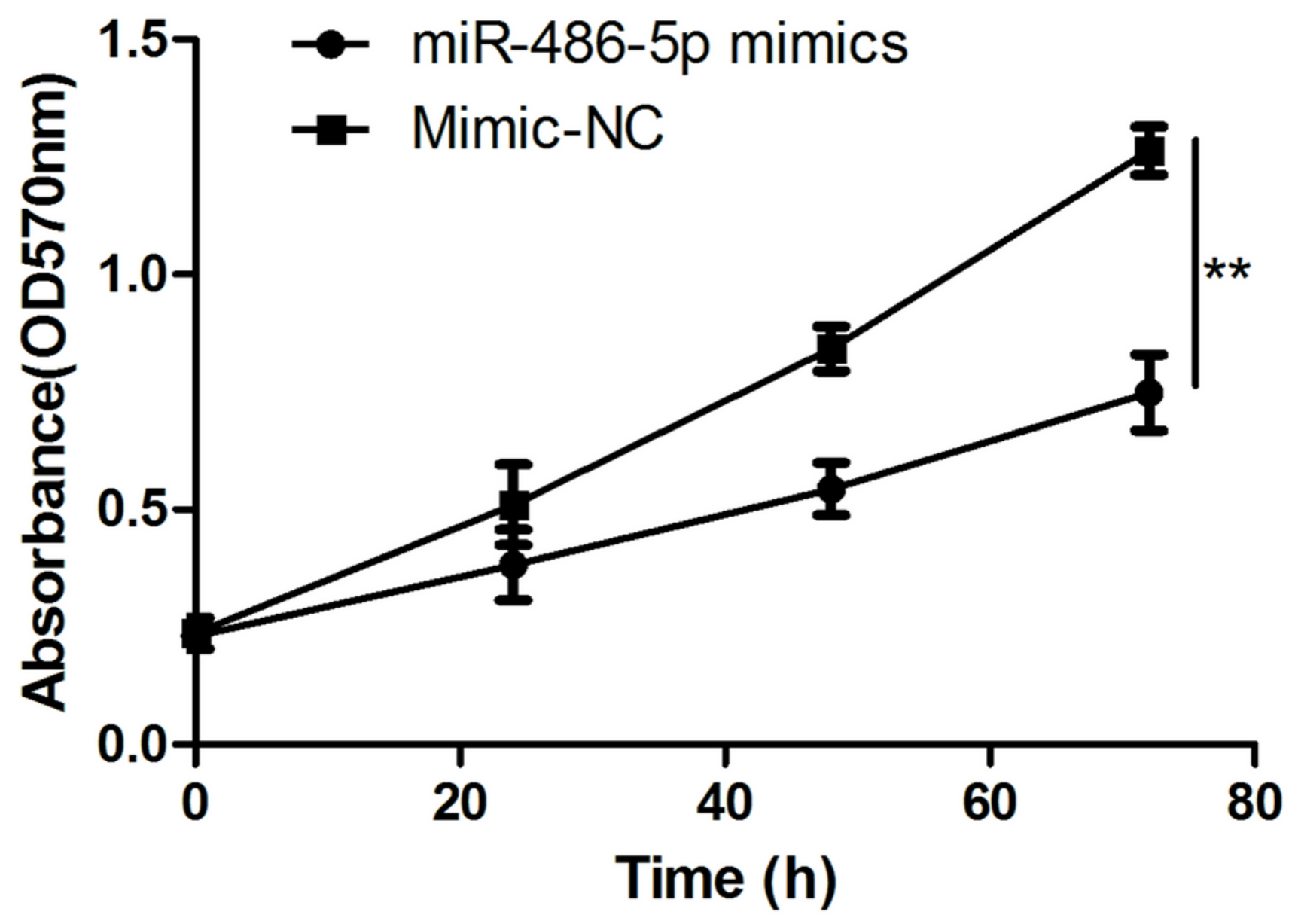

Figure 2

The proliferation of cartilage cells of congenital microtia was detected by MTT methods. The results showed that the proliferation ability of cartilage cells was significantly lower in miR-486-5p mimics transfection group than that in mimic-NC group. ** $\mathrm{P}<0.01$.

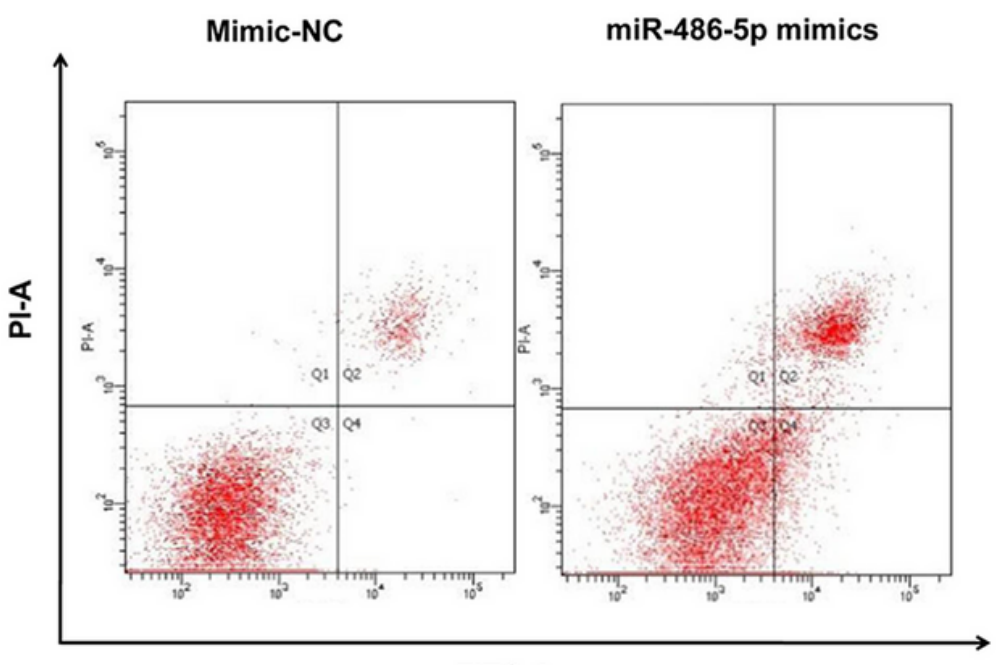

FITC-A

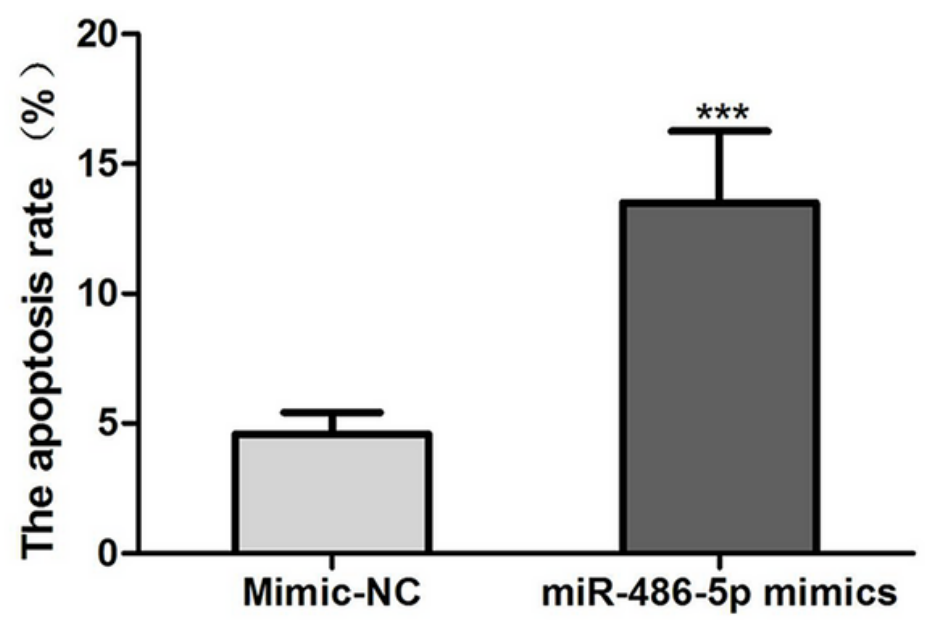


Figure 3

The apoptosis of cartilage cells of congenital microtia was checked by flow cytometry. The results showed that the apoptosis ability of cartilage cells was obviously higher in miR-486-5p mimics group than that in mimic-NC group. ${ }^{* \star} \mathrm{P}<0.001$.

A

Position 428-434 of H3F3B 3'UTR AGAGUUGAUAAAUGUGUACAGGG

hsa-miR-486-5p

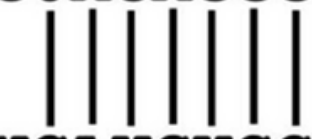

. . GAGCCCCGUCGAGUCAUGUCC

B

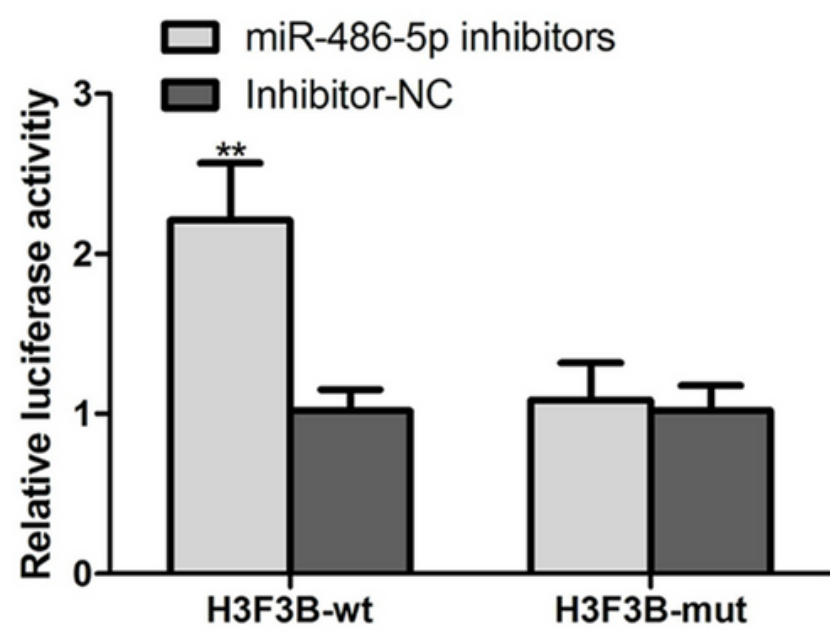

C

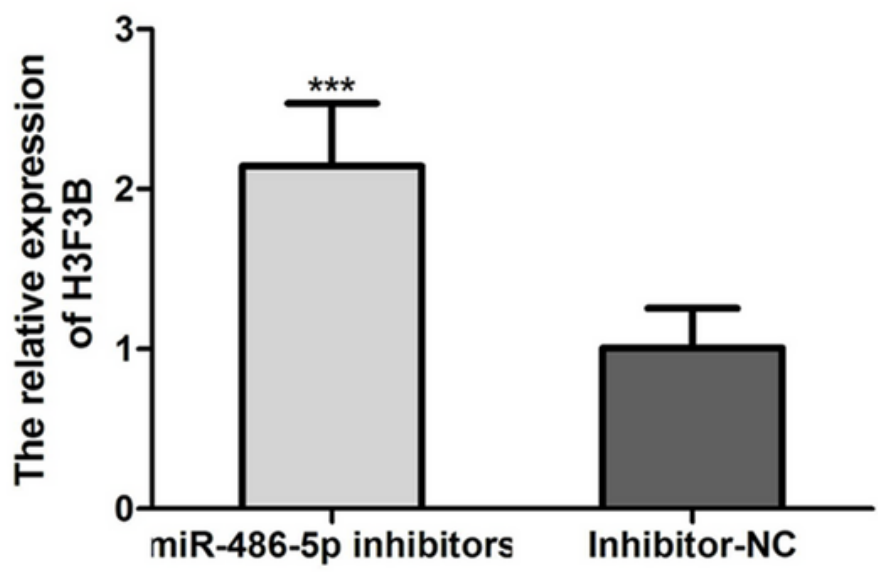

D
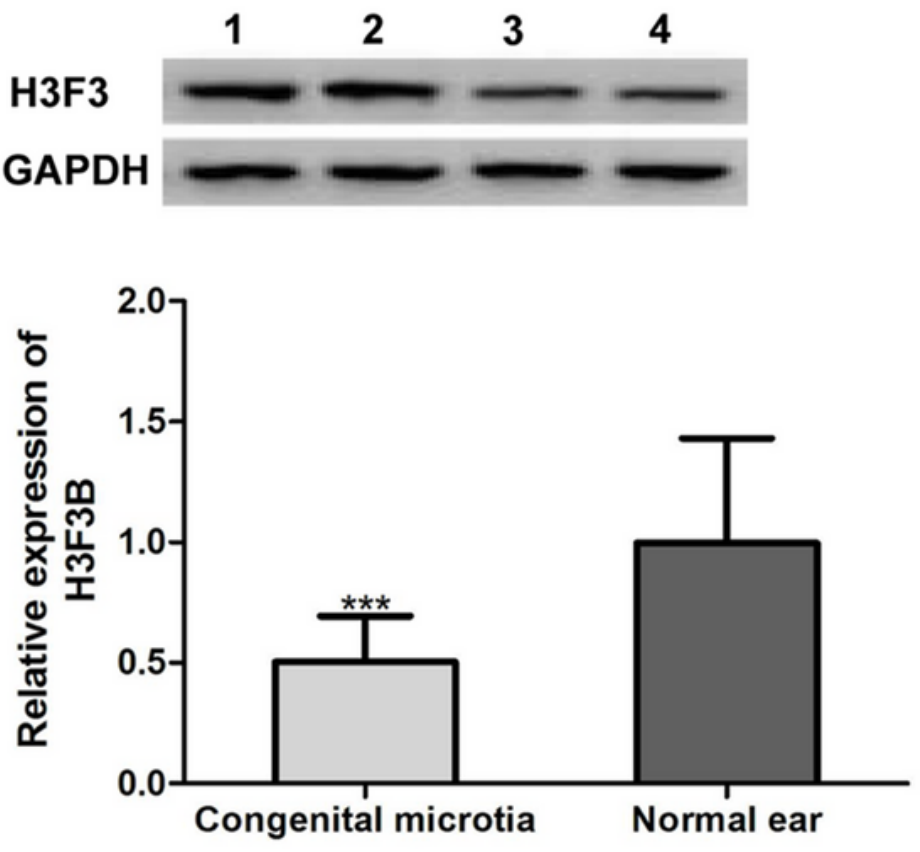

Figure 4 
The targeted relationship between miR-486-5p and H3F3B. The 3'UTR of H3F3B has the binding site of miR-486-5p (A). miR-486-5p inhibitors can obviously increase luciferase activity in cartilage cells with H3F3B-wt, compared with inhibitor group, however, the difference was not significant in cartilage cells with H3F3B-mut (B). The knockdown expression of miR-486-5p resulted in increased expression of H3F3B in cartilage cells of congenital microtia (C). The expression of H3F3B mRNA and protein in cartilage tissues of congenital microtia and normal ear. Lane 1 and 2: normal ear; Lane 3 and 4: congenital microtia (D). **: $P<0.01, * * *: P<0.001$.

A

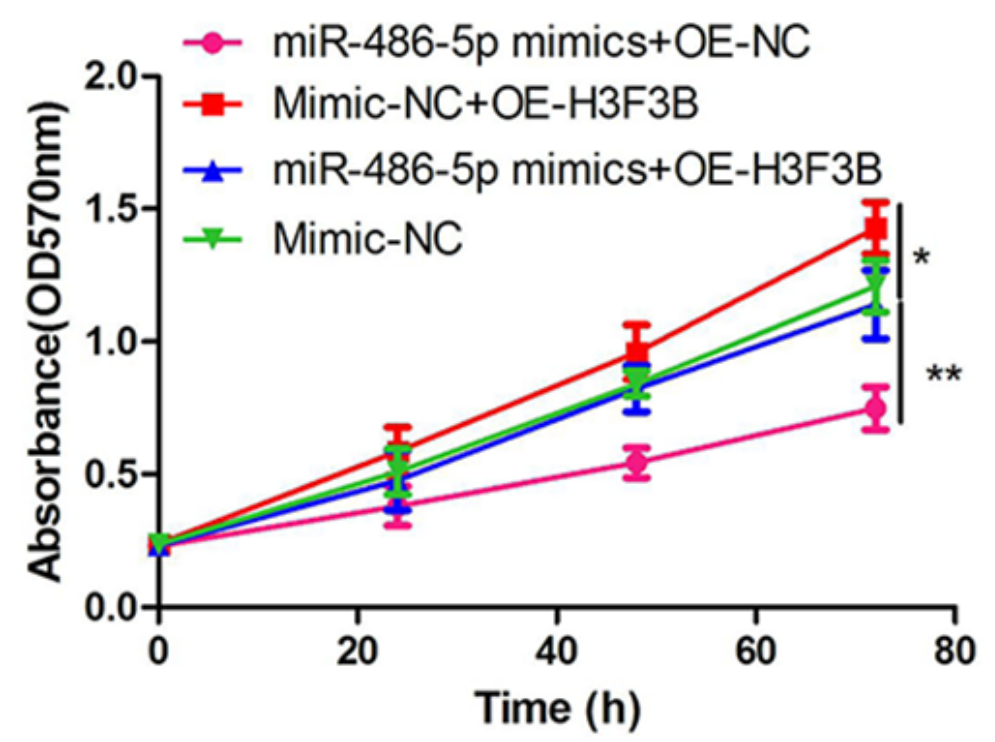

C

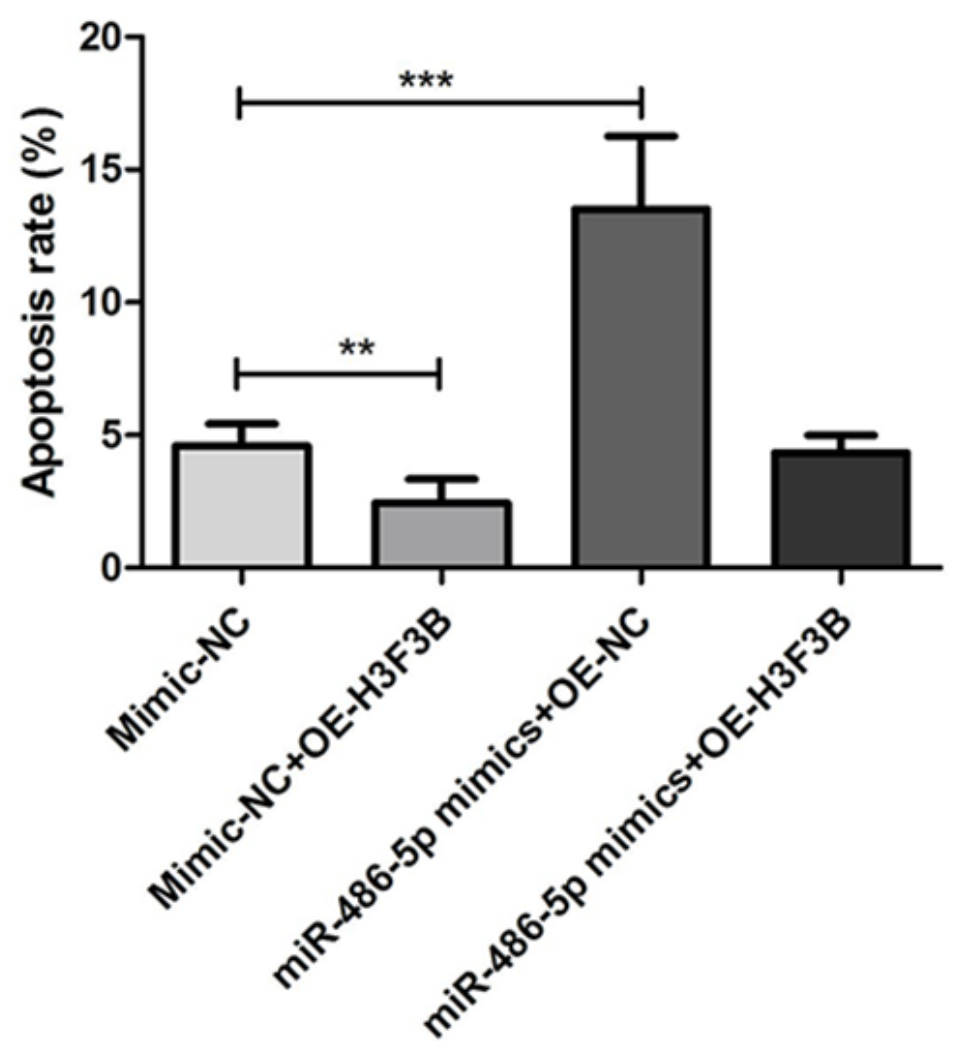

B

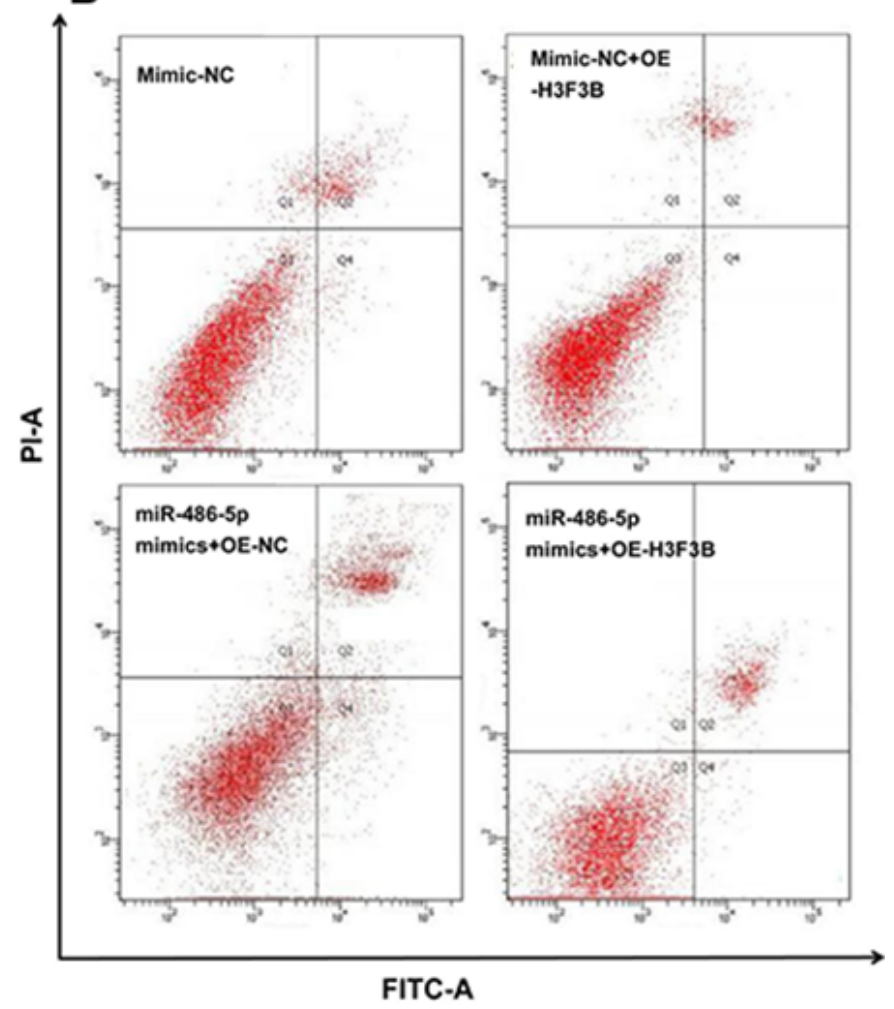

Figure 5 
miR-486-5p regulated the proliferation and apoptosis of cartilage cells in congenital microtia patients. The results showed that H3F3B overexpression reversed the inhibited role of miR-486-5p mimics transfection for the proliferation of cartilage cells (A). H3F3B overexpression expression also significantly reversed the promoted role of miR-486-5p mimics for the apoptosis of cartilage cells $(B, C) . *$ : $P<0.05$, **: $P<0.01, * * *: P<0.001$. 